Journal of the American Medical Association.

EDITED FOR THE ASSOCIATION BY N. S. DAVIS.

PUBLISHED WEEKLY.

Vol. VIII. Chicago, March 26, I887. No. I 3.

\section{ORIGINAL ARTIGLES.}

DEEP TUBING OF THF LARYNX AS A SUBSTITUTE
FOR INTUBATION.

With a Report of Nine Cases and Presentation of New Instruments.

Read before the Chicago Medical Society, March 7, 1887. BY A. E. HOADLEY, M.D.,

PROFESSOR OF ANATOMY, CHICAGo COLLEGE OF PHYSICIANS AND SURGEONS, PROFESSOR OF SURGERY IN THE CHICAGO POLICLINIC, ETC:

In April, 1886, I became convinced that intubation of the larynx was a justifiable surgical procedure, and a valuable substitute for tracheotomy in selected cases. I therefore procured a set of the O'Dwyer instruments and tubes. Although I had handled the tubes and seen them introduced, and a year previous had introduced them myself on the cadaver, I did not until this time give serious consideration to the position of the tube after the introduction. I had no difficulty in coming to a conclusion in this matter. From my knowledge of the larynx, and the contour of the head of the tube, I decided that the head of the tube was designed to rest within the larynx, with its projecting flange resting upon the false vocal cords, with the straight part of the tube behind resting against the posterior straight wall of the larynx. (Fig. I.)

It was not until I had in this manner tubed five cases that $I$ was informed that it was not the design of the inventor, Dr. O'Dwyer, to have the head of the tube rest within the larynx, but on the contrary to have the flange project laterally and posteriorly above the opening into the larynx, resting upon the arytenoid cartilages behind, and the aryteno-epiglottidian folds on each side, with the head of the tube in such a position that when the epiglottis is closed, it would come in direct contact with the tube, closing its orifice but allowing its flange to project beneath it. (Fig. 2) It now became necessary for me to either acknowledge my error and turn the tube around, or justify the position and claim an improvement. I examined the five cases and was fully convinced that the deep position was at least worthy of further trial. $I$ can now present a summary of nine cases which I have thus treated. Seven of the operations were performed for other physicians; for Drs. R. N. Hall, G. M. Emrick, E. E. Holroyd, Wm. Rittenhouse and Caldwell. Two were performed where there had been no physician in attendance until $I$ was called and found it necessary to tube immediately. I have not as yet had an opportunity of watching the patients as closely as I could desire, and for the main facts relative to the subsequent behavior of the patients $I$ am indebted to the physician in attendance. Of the two cases above referred to, I saw one six hours after the operation. She was perfectly comfortable as far as breathing and wearing the tube were concerned. The other died twelve hours after the operation, before I saw her a second time.
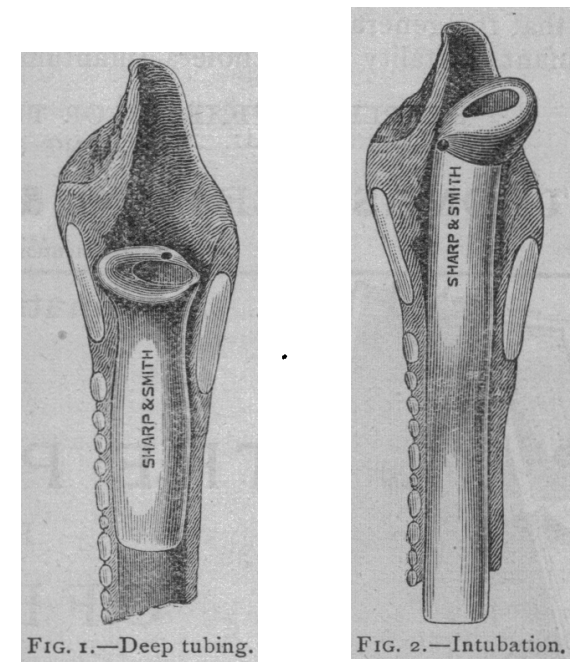

The ages of the patients ranged from 2 to 6 years. All had diphtheritic laryngeal stenosis. They were all bad cases and all died in from twenty-four hours to four days after the operation. The stenosis was promptly relieved in all. Eight out of the nine were able to drink several consecutive swallows immediately after the operation, and continued to do so as long as they could swallow. The eight suffered little or no pain from the presence of the tube, nor was the cough particularly troublesome. Four coughed but very little. In one the presence of the tube in the larynx did not excite cough; on the contrary, there was less coughing than before the tube was introduced. In one case the tube was coughed out, and a larger tube was introduced, which remained until the child died from extension of the exudate below the tube. In no case was there subsequent obstruction above the tube. In one case the obstruction seemed to be in the fauces and pharynx, and I feared that tracheotomy would be necessary, but "deep tubing" gave prompt relief. In two cases while 
pressing the tube down deep into the larynx, it was felt to slip by an obstruction and pass beyond reach. In these two cases I believe the head of the tube was lodged in the ventricle of the larynx, resting upon the true vocal cords. There was no unusual inconvenience from the presence of the tube in this situation. I removed the tube in one of these cases and I had as little difficulty as in any, which I think would be equally true had the child been living. I might state while giving this opinion, however, that I have never extracte $d$ a tube from the living subject.

One case suffered severe and continual pain from the presence of the tube, and could not drink one drop without strangling and having a violent fit of coughing following the attempt; she was fed by means of a tube in the osophagus. She died on the fourth day from pneumonia, the development of which was probably favored by the irritation of the tube. This was Olga L., a girl 5 years of age, a patient of Dr. Emrick's. About two years previous, she swallowed, by mistake, some concentrated lye, causing extensive destruction of the tissue followed by a violent inflammation. After a long and desperate struggle she recovered her general health; but there remained two almost impervious strictures of the cesophagus. She had been under my care six months for the surgical treatment of the strictures when she contracted diphtheria, for relief of which the "dèep tubing" was practised. It was to these changes in the pharynx and oesophagus caused by the lye that I attributed her intolerance of the laryngeal tube.

In seven cases death was caused by constitutional diphtheria, in one by extension of the exudation below the tube, and in one from pneumonia. While this summary of nine fatal cases of intubation of the larynx for diphtheria would show that intubation does not cure; it does not prove that intubation is an unjustifiable practice. On the contrary, it shows that the practice is one capable in the simplest manner of affording the greatest possible relief and allowing the patient to die a less horrible death than that of suffocation, and at the same time give one more chance for life.

In comparing the two methods of introducing the tube, I would call attention to what I regard as the most objectionable feature of the O'Dwyer method. It is the projection of the head of the tube over the top of the larynx in such a manner that it prevents the glottis from folding down and adapting itself to the top of the larynx in the usual manner. This leaves a margin of laryngeal mucous membrane exposed, which has been in the habit of being covered at every act of deglutition. The projections of the tube do not cover it perfectly, so that in every act of swallowing the food is allowed to come in contact with this surface, which is excessively sensitive to everything but air, and must necessarily excite coughing. I have no doubt but what the glottis will close the orifice of the tube perfectly, thus preventing any food from getting into the tube, but it carnot close the laryn $x$ by the side of the tube, and food, fluids especially, are forced into the larynx, thus causing the most distressing paroxysms of coughing at every attempt at swallowing. All this is obviated by the method that I have adopted, as the head of the tube is within the larynx and well below the opening, so that the glottis does not touch the tube and can therefore perfectly guard the larynx.

In reference to the removal of the tube, it is my opinion that the tube can be more quickly engaged by the extractor while it rests within the larynx, than while the head of the tube rests above the larynx. The head of the tube being surrounded by the upper extremity of the larynx, greatly facilitates the operation, as it is not easy to get the extractor down by the side of the tube, which is the source of the greatest annoyance with the tube in the high position. With reference to the danger of introducing the tube into the trachea, I would state that it is certainly a remote danger, as any one will admit that attempts to push the head of a well fitting tube beyond the chink.

The modifications in the tube that have suggested themselves for the better adaptation to this mode of intubation, and which have been constructed for me by Sharp \& Smith, of Chicago, are:

Shortening the tube to the length of the larynx, or perhaps a trifle longer. (Figs. I and 3.)

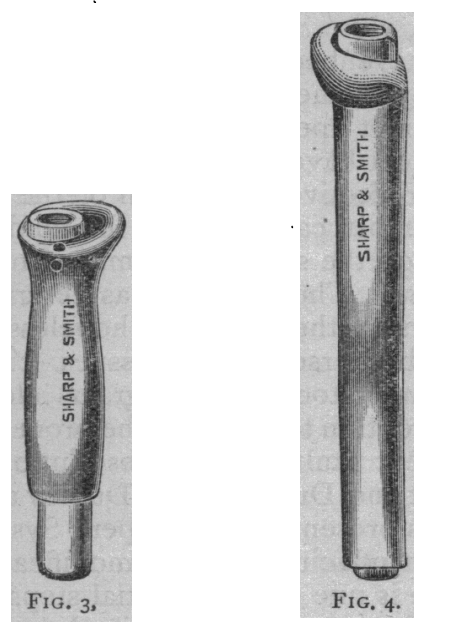

Making the head of the tube conform more nearly to the shape of the interior of the upper part of the larynx.

Making the upper surface of the head of the tube slightly cup-shaped for the purpose of favoring the introduction of the extractor.

Having that portion of the posterior border of the tube, which corresponds to the arytenoid cartilages stand on a plane anterior to that of the rest of the tube, so that the pressure at this point may be slight. As the arytenoids are supported by muscles we should avoid putting them on the stretch. Constructing the obturator so that it will project threeeighths of an inch from the lower end. My tube, being a little shorter than the most convenient length for introduction, the longer tip of the obturator enables one to pass the tip to the proper position below the chink, when the tube should be detached, and pressed home with the finger before the obturator is withdrawn. 
The greatest objection to using the tubes of the pres- the support given by the perineal body below. The ent construction for "deep tubing" is their length. The only aid this body could give the supposed support O'Dwyer tubes (Fig. 4) when placed deep in the lar- would be by the uterus resting directly upon it. Dr. ynx, will reach to the seventh ring of the trachea, as Emmet puts it very happily when he says "it would shown by an autopsy. This, owing to the mobility of be as rational to assume that a man's pantaloons the lower end of the tube in the trachea in the varying were supported by the legs resting on the instep or positions of the neck, is a source of irritation excit- foot." The principal support of the pelvic organs is ing cough and inducing pain. One of my patients their ligamentous attachments, on the same principle would invariably point to that locality when asked to locate the tube.

Finally, I would recommend "deep tubing" of the larynx as being preferable to "intubation," even though the long tubes are used, holding that long tubes are preferable only in very exceptional cases.

No. 683 Washington Boulevard.

EMMET'S NEW OPERATION FOR PROLAPSE OF THE POSTERIOR VAGINAL WALL,

Or So-called Laceration of the Perineum.

\section{Abstract of a Paper read before the Obstctrical Society of Philadelphia, February 3, 1887, \\ BY J. M. BALDY, M.D., OF PHILADELPHIA,}

Since I have become familiar with the subject it has each day seemed more incomprehensible to me why the Emmet operation has not come into more general use. I have come to the conclusion that the fault lay in defective description of the operation as set forth in most cases, and in the fondness of men for working on the skin perineum, and not in the operation per se. The operation, as described by most of the writers on the subject, is hopelessly mixed up with long discourses on side issues. Too much is left to be understood from diagrams alone, with insufficient attention to details in the procedure. These are prominent faults in the descriptions given by Drs, Emmet and Dudley. Dr. Dudley also obscures his paper, as presented in "Pepper's System of Medicine," by introducing several "modifications." The first of these is one of the essential steps in the operation, though not clearly described by Dr. Emmet in the third edition of his "Gynecology." It consists in carrying the denudation into the vaginal sulci. The second consists in passing deep sutures where Dr. Emmet passes superficial ones. In reality, Dr. Emmet's "superficial" stitches are only relatively superficial. His description of them distinctly calls for their being passed deeply enough to include the posterior wall. My excuse, therefore, for offering a contribution on such an old subject, is to attempt to make the steps of this operation clear; and if I seem tedious in detail to those who are familiar with the subject, I hope you will bear with me patiently.

The belief that the female perineum, or perineal body, gives any support to the pelvic viscera, is an erroneous one. The distance between the uterus and the perineal body is quite measurable, and the intervening tissues, which consist merely of the mucous vaginal canal and surrounding connective tissue, are by no means of such a firm character as to be able to uphold the uterus either per se or through as the organs contained within the abdominal and thoracic cavities are suspended. A good proof of this is the fact that we constantly see women going about their daily work who have their superficial or skin perinea, not including the fasciæ or muscles, torn even to the sphincter ani, and who never have suffered any inconvenience therefrom, and who probably never will. The cause of all the various ailments folluwing parturition, beginning procidentias, etc., will be found inside the vagina on the posterior wall. If any one will place his fingers on the posterior vaginal wall of a woman who has never borne a child, and move them first to one side and then to the other, he will find a firm resistance to pressure in any direction. If he now introduce his finger into the vagina of a woman who has had an injury to the pelvic floor during parturition, he will fail to meet with the resistance which he met in the first case. He will find instead a rectocele of greater or less extent, with deep divulging sulci running up each side of the recto vaginocele, into which he can easily sink his finger without finding much resistance, and yet the external or skin perineum may be perfect.

To fully and clearly understand this change it will be necessary to consider the attachments of the pelvic viscera. The pelvic fascia descends until it reaches its attachment on a line drawn from the symphisis pubis to the spine of the ischium, where it divides into two layers, the outer or obturator, and the inner or recto-vesical fascia. This line of separation in great part also corresponds to the line of attachment of the levator ani and coccygeus muscles. The levator ani extends from this attachment downward, and passing under the vagina is inserted into the rectum at different points. It is covered on its upper surface by a reflexion of the recto-vesical fascia, which binds it closely to the vagina and sphincter vagina muscle, and on its under surface by a reflexion of the obturator fascia, which binds it closely below. The transversus perinei, when it exists at ail, arises from the pubic arch, and its fibres are lost in the sphincter vagina directly under the vagina. In speaking of the use of the sphincter vagina Dr. Goodell says that "the property of this muscle is to pull down the rigid clitoris into contact with the male organ, to squeeze out the contents of the vulvovaginal glands, and to compress the dorsal vein as well as the bulbs of the vagina, so as to obstruct mechanically the current of blood and produce a turgescence of these erectile organs." If this be correct, we have an explanation of the loss of sexual power and desire so often seen in women who have suffered from a tear of this muscle. The recto-vesical fascia sends out reflexions from its bony attachments also over the vagina as well as over the other pelvic contents, forming the strong ligaments which 